East African Medical Journal Vol. 80. No. 8 August 2003

USE OF A MODIFIED ALVORADO SCORE IN THE DIAGNOSIS OF ACUTE APPENDICITIS

H.S. Saidi, BSc, MBChB, MMed (Surgery), FCS (ECSA), Lecturer, Department of Human Anatomy, College of Health Sciences, University of Nairobi, P.O Box 30197,

Nairobi, Kenya and S.K. Chavda, MBChB, MMed, Surgeon, Kilifi District Hospital, Kilifi, Kenya.

Request for reprints to: Dr. H.S. Saidi, Department of Human Anatomy, College of Health Sciences, University of Nairobi, P.O. Box 30197, Nairobi, Kenya.

\title{
USE OF A MODIFIED ALVORADO SCORE IN THE DIAGNOSIS OF ACUTE APPENDICITIS
}

\author{
H.S. SAIDI and S.K. CHAVDA
}

\begin{abstract}
Background: The negative appendicectomy rates have remained high. The integration of clinical scores into the diagnostic process in acute appendicitis has had the purposes of improving decision making and reducing the negative rates in this common condition. The performance of these score systems have however, not been uniform.

Objective: To assess the usefulness of a modified Alvorado score (1986) to predict groups of patients with suspected appendicitis for definite surgery, observation or discharge from hospital.

Design: Prospective study.

Setting: Kenyatta National Hospital (KNH), a central referral and teaching hospital in Nairobi, Kenya.

Patients: One hundred and eighty nine patients with suspected acute appendicitis were studied over a period of twelve months.

Methods: Five symptoms and four signs were assigned numerical values and the patients scored out of a total of 10 points. A score of $>7$ predicted mandatory operation, 5-6 observation and score 1-4 predicted those not considered for surgery. The decision to operate was the prerogative of the surgeon or surgical resident based on overall clinical suspicion and not the diagnostic score.

Results: The proportion of patients with scores $>7$ was $40.7 \%$. The mean score was 6.02 . The mean ages and the gender ratios were similar across score groups. The negative appendicectomy rate was $17.6 \%$ for group $1-4,16.5 \%$ for $5-6$ and $19.7 \%$ for $>7$. These were similar to the overall negative rate of $18 \%$ based on clinical suspicion. The overall sensitivity and sensitivity for the scoring system was $80.3 \%$ and $16.8 \%$ respectively.

Conclusion: High scores were found to perform poorly in predicting diagnosis of acute appendicitis preoperatively and in the reduction of negative appendicectomies. The integration of a scoring system does not offer advantage over degree of clinical suspicion.
\end{abstract}

\section{INTRODUCTION}

Reginald Fitz first described appendicitis in 1886 and a few years later, Charles McBurney described the clinical findings prior to rupture and advocated early surgical intervention (1). Today, over 100 years later, the accurate diagnosis still remains difficult. An average of $20 \%$ of appendices removed for presumed appendicitis are normal. While the diagnosis is relatively straightforward in young men, the error rate in pre-menopausal women can approach $40 \%(2,3)$. The morbidity and financial implications of these errors are immense. Attempts made to reduce these diagnostic errors have involved the creation of scoring systems based on a combination of historical factors, physical examination and laboratory variables elicited from the patient and given numerical values to predict the likelihood of appendicitis. The Alvorado, Mantrell, Christian, Fenyo scores are often quoted (4). These variables include the male sex, leucocytosis, neutrophilia, history of less than 24 hours, anorexia, nausea/ vomiting, shift of pain from epigastrium, rebound tenderness and localized guarding (4-6).
The incidence of appendicitis is increasing in the urban centers of countries in Africa (7). It is not clear whether diagnostic scores would be applicable for our groups of patients. Elsewhere, the performances of these score systems have ranged from good to poor (4).

This study evaluated a scoring system modified from that of Alvorado in consecutive patients undergoing appendicectomy for suspected acute appendicitis at the Kenyatta National Hospital.

\section{MATERIALS AND METHODS}

Setting: Kenyatta National Hospital, a 2000-bed tertiary referral facility and a University teaching hospital in the city of Nairobi.

Design and Duration: Single center evaluation with a prospective data base. The study was performed from July 2000 to June 2001.

Subjects: One hundred and eighty nine patients with clinical suspicions of acute appendicitis and undergoing appendicectomy were analysed. Patients were admitted into the general surgical wards from the Emergency department and reviewed by general 
surgery residents who made the decisions to operate. The authors abstracted patient data by individual chart review. Data were collected on medical history, physical findings, demographics, diagnostic tests, operation findings and histopathological findings of removed appendices. An appendicitis score was calculated for each patient. The score covered 5 symptom variables and four signs given numerical values 1 or 2 . The maximal cumulative value was 10: duration of symptoms $<48$ hours one, relocation of pain one, anorexia one, nausea/vomiting one, right iliac fossa pain one, right iliac fossa tenderness one, rebound tenderness/ rigidity/guarding one, fever one, Rovsing/Psoas sign one. The patients were divided into three score groups. The decision to operate was however not based on these scores but the clinical impression by the clinician taking charge of the patient.

Group I (score 7-10):- surgery, Group II (score 5-6):admission and observation, Group III (score 1-4):- surgery not indicated.

Main Outcome Measures: The measures included the proportion of patients in each score group and the rate of positive histology. All the appendices removed were sent for histopathological examination.

Statistics: Descriptive summary statistics for age and appendicitis scores were performed. $\mathrm{X}^{2}$ analysis was used to analyse differences in the proportions of negative appendicectomies between the diagnostic score groups. The student t-test analysis was utilised to compare mean scores across groups. $\mathrm{p}<0.05$ was considered statistically significant.

\section{RESULTS}

One hundred and eighty nine patients who underwent appendicectomy for suspected acute appendicitis were analysed. There were 116 males $(61.4 \%)$ and 73 females. The average age was $27.8 \pm 13$ years (range 5-80 years of age). The peak age category was $21-30$ years $(36.5 \%)$.

The appendicitis scores ranged from two to ten. The mean score was $6.06 \pm 2$. The proportion of patients with scores $\geq 7$ was $40.2 \%$. The proportion that scored 5-6 was $41.8 \%$. Thirty four patients $(18.0 \%)$ had a score of $1-4$. The mean age was 26.9 years for score group 1-4, 28.5 years for group 5-6 and 27.8 years for the score group 710. The gender proportions were similar across the groups (males comprised $64.5 \%$ of group $7>55.7 \%$ of group 5-6 and $65.8 \%$ of group $1-4 ; p>0.05$ ) (Table 1 ).

Histological evidence of inflammation was obtained in $88.4 \%$ of appendices in score group I-4 and $83.5 \%$ of score group 5-6 $(p=0.877)$. Positive histology was obtained in $80.3 \%$ of patients in group $\geq 7$. When dichotomised into less or greater/equal to 7 , the proportion of positive histology of the combined group 1-6 did not differ significantly from score group $7-10(p=0.608)$. Conversely the negative appendicectomy rates of $17.6 \%$ in group 1 $4,16.5 \%$ in groups $5-6$ and $19.7 \%$ in group 7-10 (Figure 1), were comparable to the overall negative appendicectomy rate of $18.0 \%$ based on physician judgment alone.
The overall sensitivity of the modified score in this study was high $(80.3 \%)$ but the specificity was low (16.8\%). The signs and symptoms predictive of appendicitis also had high sensitivities but suffered from low specificities (Table 2a,b). Pain in the right lower quadrant had a sensitivity and sensitivity of $80.6 \%$ and $14.3 \%$ respectively. Abdominal rigidity had a sensitivity of $84.4 \%$ and specificity of $25 \%$. Migration of pain from the periumbilical region had a sensitivity of $83.3 \%$ and specificity of $22.2 \%$. The overall sensitivity was highest among males $(94.0 \%$ while that in females was $70.4 \%)$. The results of the white cell count analysis are shown in Table 3. The mean leucocyte count showed a significant difference between the groups $1-4$ and 5-6 (17.6 x 109/1 vs $\left.14.025 \times 10^{9} / 1 ; p=0.004\right)$. The low acuity group of patients (1-4) also had a higher mean leucocyte count when compared to group 7-10 (15.74 X 10\%/l). For categorical groups for gender, faecolith presence and symptom duration, $\mathrm{X}^{2}$ analysis did not demonstrate any statistically significant difference in the leucoyte data. There were faecoliths in $29.4 \%$ of appendices in score group 1-4, $39.24 \%$ of appendices in 5-6 and $40.8 \%$ in score group 7-10.

Table 1

Characteristics of clinical score groups

\begin{tabular}{llrcc}
\hline & & $\begin{array}{c}1-6 \\
(\mathrm{n}=113)\end{array}$ & $\begin{array}{c}7-10 \\
(\mathrm{n}=76)\end{array}$ & $\mathrm{p}$-value \\
\hline \multirow{2}{*}{ Inflammation } & Yes & 94 & 61 & 0.608 \\
& No & 19 & 15 & \\
Fex & Male & 66 & 50 & 0.307 \\
\multirow{5}{*}{ Complication } & Female & 37 & 26 & \\
& Present & 41 & 31 & \\
& Absent & 79 & 45 & 0.532 \\
& Yes & 18 & 5 & \\
& No & 95 & 71 & 0.054 \\
\hline
\end{tabular}

Table 2 a

Symptom profile across clinical score groups

\begin{tabular}{lccc} 
Characteristic & $1-4(\mathrm{n}=34)$ & $5-6(\mathrm{n}=79)$ & $7-10(\mathrm{n}=76)$ \\
\hline Pain duration $(\leq 2$ days $)$ & $6(17.6)$ & $23(67.1)$ & $56(73.7)$ \\
Umbilical pain & $23(67.6)$ & $50(63.3)$ & $71(93.4)$ \\
Right iliac fossa pain & $16(47.0)$ & $71((89.9)$ & $75(98.7)$ \\
Anorexia & $9(36.0)$ & $20(25.3)$ & $38(50)$ \\
Nausea/vomiting & $21(61.8)$ & $48(60.8)$ & $57(75)$ \\
Fever & $3(8.8)$ & $11(13.9)$ & $11(14.5)$ \\
Right iliac tenderness & $10(29.4)$ & $75(94.9)$ & $76(100)$ \\
Rebound/guarding & $18(52.9)$ & $64((81)$ & $75(98.7)$ \\
Psoas/Rovsing & $0(0)$ & $6(7.6)$ & $27(35.5)$ \\
& & & \\
\hline
\end{tabular}


Figure 1

\section{Negative appendicectomy rates in score groups}

Table 2b

Sensitivity and specificity of clinical findings for the diagnosis of acute appendicitis

\begin{tabular}{lcc}
\hline Finding & Sensitivity (\%) & Specificity (\%) \\
\hline Migration pain & 83.3 & 22.2 \\
Right lower quadrant pain & 80.6 & 14.3 \\
Anorexia & 85.6 & 19.6 \\
Nausea/vomiting & 83.3 & 4.8 \\
Gurading/rigidity & 84.4 & 25.0 \\
Rebound tenderness & 85.0 & 21.3 \\
Right quadrant tenderness & 80.1 & 7.6 \\
\hline
\end{tabular}

Table 3

White cell count versus score group inflammation and faecolith presence

\begin{tabular}{|c|c|c|c|c|}
\hline & & Mean count & SD & P-value \\
\hline \multirow[t]{4}{*}{ Score group } & $1-4$ & 17.7 & 2.7 & \\
\hline & $5-6$ & 14.0 & 1.9 & 0.004 \\
\hline & $1-6$ & 15.2 & 2.7 & - \\
\hline & $7-10$ & 15.7 & 3.5 & 0.654 \\
\hline \multirow[t]{2}{*}{ Faecolith } & Yes & 15.16 & 3.5 & 0.647 \\
\hline & No & 15.6 & 2.7 & - \\
\hline \multirow[t]{2}{*}{ Gender } & Male & 15.0 & 3.1 & 0.436 \\
\hline & Female & 15.9 & 3.0 & - \\
\hline \multicolumn{5}{|c|}{ Symptom duration } \\
\hline & 24 hours & 15.7 & 3.1 & 0.293 \\
\hline & 24-48 hours & 12.7 & 2.1 & - \\
\hline & $>48$ hours & 13.7 & 0.35 & - \\
\hline
\end{tabular}

\section{DISCUSSION}

Our results show that $40.2 \%$ of the patients satisfied the criteria for a definite diagnosis of acute appendicitis. Another $41 \%$ for probable appendicitis. Nearly a fifth $(18 \%)$ of the patients were predicted to have alternative diagnoses. The clinical score had a high sensitivity (80.3\%) but suffered from low (16.8\%) specificity. Of patients with scores of $\geq 7$ the negative appendicectomy rate was
$19 \%$. The overall error rate of $18 \%$ (from clinical suspicion) was similar to that predicted by scoring.

Our results have failed to validate the use of a clinical score in predicting appendicitis. Patients with acutely inflamed appendices did not fulfill more clinical criteria than those without. The overall sensitivity (proportion of group $>7$ with positive histology) was $80.3 \%$. The specificity (proportion of those 1-6 with negative histology) was only $16.8 \%$. In a study of 68 patients, Crnogorac et al. found a large proportion $(82.7 \%)$ of patients with Alvorado score 7 or more. The score was found useful with sensitivity and specificity levels of $87 \%$ and $60 \%$ respectively being achieved (8).

The similar rates of positive histology for both high and low total scores in our study indicate that the accuracy of a diagnosis of appendicitis is not improved by a combination of historical and physical examination findings. These findings appear to support the results by Izbicki et al. (9). In their study, the male sex, white cell count greater than 11 X $10^{\%} / 1$, history of less than 24 hours, rebound tenderness, shift of pain from epigastrium and localised guarding were predictive retrospectively, but were characterised by low specificities and sensitivities when applied prospectively. Combining the scores did not improve their predictive power. The authors concluded that the accurate diagnosis of appendicitis depended largely on the experience of the surgeon and not by application of a score system that included the above variables (9).

The limited utility of the clinical parameters due to low specificities may be due to the protean nature of presentation of appendicitis and a myriad of other diagnoses mimicking appendicitis. No single clinical variable can therefore guarantee the correct diagnosis. Literature suggests that the signs and symptoms that seem to be most predictive of appendicitis include pain in the right lower quadrant, abdominal rigidity, migration of pain from the umbilical region to the right lower quadrant (10) and a short history (11). For right lower quadrant pain and rebound tenderness the sensitivity values approach $81 \%$ and $63 \%$ respectively. The specificities approach $53 \%$ and $69 \%$ (10). The low specificity of symptoms and peritoneal signs leaves clinical experience as the most helpful item in proving the diagnosis of acute appendicitis which ought to be operated upon (12). The high sensitivities of peritoneal signs may mean that their absence may be more useful in ruling out the diagnosis of acute appendicitis.

The lower overall sensitivity of the score in females is expected. Bhattacharjee et al. (13), analysing 110 patients, found a sensitivity of $94.1 \%$ in males and lower value of $71.9 \%$ in females for a modification of the Alvorado score. Pre-menopausal females have a number of gynaecological conditions with presentations similar to appendicitis. The common misdiagnoses include pelvic inflammatory disease, gastroenteritis, urinary tract infection, ruptured ovarian follicle and ectopic pregnancy (14). For their group of women with normal appendices who underwent operation, alternative diagnoses included pelvic inflammatory disease, ruptured follicular cysts, twisted 
ovarian cysts and ruptured ectopic pregnancy (13).

The mean white cell count was highest for the low acuity patients (score 1-4). All the patients who had this examination carried out ( $16.9 \%$ of the total) demonstrated leucocyte counts more than 11 X $10^{\%} / \mathrm{L}$. The mean white cell counts did not differ across the groups. The leucocyte count was also similar for those with or without appendicitis. These findings support the contention that although $70-90 \%$ of patients with acute appendicitis have an elevated count, leucocytosis is also characteristic of several other acute abdominal and pelvic diseases and thus has poor specificity for the diagnosis of acute appendicitis (15-18).

In conclusion, this prospective study has shown that a diagnostic scoring system does not improve upon physician judgment in patients with abdominal pain suggestive of appendicitis. Superiority and reliability of history and examination is most important in differentiating acute appendicitis from other causes of acute abdomen.

\section{REFERENCES}

1. Condon, R.E., and Telford, G.L. Appendicitis. In: Townsend CM, eds. Sabiston textbook of surgery: The Biological Basis of Modern Surgical practice. 14th ed. Philadelphia, Pa: WB Saunders and Co; 1991: 884-898.

2. Mutter, D., Vix, M., Bui, A., et al. Laparoscopy not recommended for routine appendectomy in men: results of a prospective randomized study. Surgery. 1996; 120:71-74.

3. Andersson, R.E, Hugander A., and Thulin, A.F. Diagnostic accuracy and perforation rate in appendicitis: association with age and sex of the patient and with appendicectomy rate. Eur. J. Surg. 1992; 158:37-41.

4. Ohman, C., Yang, Q. and Franke, C. Diagnostic scores for acute appendicitis. Abdominal pain study group. Eur. J. Surg. 1995; 161: 273-281.
5. Alvorado, A.A practical score for the early diagnosis of acute appendicitis. Ann. Emerg. Med. 1986; 15:557-564.

6. Teicher, I., Ianda, B., Cohen, M. and Kabnick, L.S, Wise I Scoring system to aid in diagnosis of appendicitis. Annals. Surg. $1983 ; \mathbf{1 9 8 : 7 5 3 - 7 5 9 .}$

7. Madiba, T.E, Haffejee, A.A., Mbete. DLM, Chalthram, H, and John, J. Appendicitis among African patients at King Edward VIIIa Hospital, Durban, South Africa: A Review. East Afr. Med. J. 1998; 75:81-84.

8. Crnogorac, S. and Lovrenski, J. Validation of the Alvorado score in the diagnosis of acute appendicitis. Medicinski Pregled. 2001; 54:557-561.

9. Izbicki, J.R., Knoefel, W.T., Wilker. D.K., et al. Accurate diagnosis of acute appendicitis: a retrospective and prospective analysis of 686 patients. Eur. J. Surg. 1992; 158:227-231.

10. Wagner, J.M., McKinney, W.P., and Carpenter, J.L. Does this patient have appendicitis'? JAMA. 1996; 276:589-594.

11. John, H., Neff, U. and Keleman, M. Appendicitis diagnosis today: clinical and ultrasonic deductions. World J. Surg. 1993; 17:243-249.

12. Luhman, J., Schneider, A. and Braun, L. Diagnosis of appendicitis: only experience helps. Medizinische Klinic. 1980; 75:303-306.

13. Battcharjee, P.K., Chowdhury, T. and Roy, D. Prospective evaluation of modified alvorado score for diagnosis of acute appendicitis. J. Indian Med. Ass. 2002; 100: 1-3.

14. Rothrock, S.G., Green, S.M. and Dobson, M., Colucciello S. and Simmons C.M. Misdiagnosis of appendicitis in nonpregnant women of childbearing age. J. Emerg. Med. 1995; 13:1-8.

15. Paulson, E.K., Kalady, M.F, and Pappas, T.N. Suspected appendicitis. New. Engl. J. Med. 2003; 348:236-242.

16. Hale, D.A., Molloy, M., Pearl, R.H., Schutt, D.C. and Jaques, D.P., Appendectomy; a contemporary appraisal. Ann. Surg. 1997; 225:252-261.

17. Lewis, F.R., Holcroft, J.W. and Boey, J. Appendicitis: critical review of diagnosis and treatment in 1,000 cases. Archives Surg. 1975; 110:677-984. 